\title{
Thermal diffusivity of in-situ exfoliated graphite intercalated compound/polyamide and graphite/polyamide composites
}

\author{
S. R. Kim ${ }^{1 *}$, M. Poostforush ${ }^{1}$, J. H. Kim ${ }^{1}$, S. G. Lee ${ }^{2}$ \\ ${ }^{1}$ Department of Polymer Science and Engineering, Chungju National University, 380-702 Chungju, Korea \\ ${ }^{2}$ Information Research Center, Korea Research Institute of Chemical Technology, 360-154 Daejon, Korea
}

Received 13 November 2011; accepted in revised form 8 January 2012

\begin{abstract}
The thermal diffusivity of graphite intercalated compound (GIC)/polyamides (PA6, PA66 and PA12) and graphite/polyamides composites were investigated. The polyamides/GIC composites were prepared by an in-situ exfoliation melting process and thermal diffusivity of the composites was measured by a laser flash method. The surface chemistry of the GIC and graphite was investigated using Fourier transform infrared spectroscopy, the fracture morphology of the composites was observed by field emission scanning electron microscopy. The thermal diffusivity of the in-situ exfoliation processed PA/GIC composites showed a significant improvement over those of PA/expanded graphite intercalated compound composites and PA/graphite composites. We suggest that the larger flake size and high expansion ratio of the GIC during the in-situ exfoliation process leads to 3-dimensional conductive pathways and high thermal diffusivity. Thermal diffusivity of the polyamides/GIC (20 vol\%) composites was increased approximately 18 times compared to that of pure polyamides.
\end{abstract}

Keywords: polymer composites, thermal diffusivity, graphite intercalated compound

\section{Introduction}

Thermal diffusivity is a measure of the rate of heat propagation through a material and it is an important property in nonsteady-state heat transfer, which occurs during the heating and cooling of a material [1]. Thermal diffusivity is crucial in certain practical applications and polymer composites with high thermal diffusivity can potentially be used in electronic circuit boards, heat sinks and light weight thermal management systems. The reliability of electronic devices is exponentially dependent on the operating temperature and quick dissipation of heat could increase the service life of these devices. To increase the thermal diffusivity of polymers, the addition of suitable inorganic or metallic fillers to the polymeric matrix is effective and convenient [2].
Graphite has a layered structure composed of alternating carbon layers. The carbon atoms are in-plane covalently bonded while carbon layers are bound by much weaker van der Waals forces. Graphite appears to be one of the most promising fillers in that could produce composites with excellent thermal, mechanical, and electrical properties at a reasonable cost. Graphite intercalated compound (GIC) expands up to few hundred times their initial volume at high temperatures and the expanded graphite sheets could exfoliate to a nanoscale level along the $c$-axis of the graphene layers [3, 4]. GIC has high conductivity and it could be a good candidate for thermal management systems and could be used in many applications where high thermal dissipation is required. The exfoliated nanosheets of GIC could

\footnotetext{
${ }^{*}$ Corresponding author, e-mail: srkim@cjnu.ac.kr
}

(c) BME-PT 
form continuous thermal conductive pathways and groups like $-\mathrm{OH}$ and $-\mathrm{COOH}$ in the exfoliated graphite sheet may result in good miscibility with both nonpolar and polar molecules [5]. There are many reports on the use of preheat-treated GIC as a filler $[3,5,6]$. However, there are very few studies on the thermal diffusivity of in-situ exfoliation processed graphite intercalated compound based composites. Uhl et al. [7] used different expandable graphite grades to prepare PA6/expandable graphite composites and they reported the enhancement of thermal stability without any significant deterioration in mechanical properties. Zheng and Wong [8] prepared poly(methyl methacrylate)/expanded graphite to study the effect of expanded graphite on electrical and structural integrity.

In this study, we used an in-situ exfoliation process to produce the GIC based thermally conductive polyamide (PA) composites. Graphite/polyamide composites were also prepared and the thermal diffusivity of this graphite/polyamide composite was compared with that of the GIC/PAs composites. The effect of polyamide grades and processing temperature on thermal diffusivity were also investigated.

\section{Experimental}

\subsection{Materials}

Three different types of commercial grade polyamides (PA6, PA66 and PA12) were chosen as the matrix. PA6 (1011 BRT, Hyosung, Seoul, Korea), PA66 (Radipol A45, Radici Chimica, Novara, Italy), and PA12 (30303 JFX1, Ube, Osaka, Japan) were used. The properties of the polymer matrices are summarized in Table 1. GIC (SFF, Chuetsu Graphite Works, Osaka, Japan) and graphite (SC20 QKG,

Table 1. Matrix properties

\begin{tabular}{|l|c|c|c|}
\hline & PA6 & PA12 & PA66 \\
\hline Density $\left[\mathrm{kg} / \mathrm{m}^{3}\right]$ & 1140 & 1010 & 1130 \\
\hline Melting temperature $\left[{ }^{\circ} \mathrm{C}\right]$ & 224.2 & 172.6 & 266.9 \\
\hline Thermal diffusivity $\left[\mathrm{m}^{2} / \mathrm{s}\right]$ & $1.59 \cdot 10^{-7}$ & $1.22 \cdot 10^{-7}$ & $1.58 \cdot 10^{-7}$ \\
\hline Sample shape & Pellet & Pellet & Pellet \\
\hline
\end{tabular}

Qingdao Kropfmuehl Graphite, Qingdao, China) were used as thermally conductive fillers and the properties of these fillers are shown in Table 2. GIC is a sulfuric acid based graphite intercalated compound. All the materials were used as-received condition.

\subsection{Sample preparation}

PAs and fillers (without any heat treatment) were dry mixed on desired volume percentages. Three different filler volume percentages, 5, 10, and $20 \mathrm{vol} \%$, were used in the sample preparation. The exfoliated graphite nanosheets were produced from the sulfuric acid-treated intercalated graphite compound using in-situ melt processing. To prepare the expanded graphite intercalated compound (ExGIC), the weighted GIC was loaded into a crucible, put into a silicon muffle furnace (Wang-Sung, Seoul, Korea), and heat-treated at $280^{\circ} \mathrm{C}$ for $10 \mathrm{~min}$. Due to the higher expansion ratio ( 200) of GIC, a compaction step was needed after expansion to put the expanded GIC into the chamber of internal mixer and it was difficult to prepare PAs/ExGIC composites with a higher ExGIC loading.

The composites of polyamides with GIC, ExGIC and graphite were prepared by a batch-type mixer (W50EH, Brabender, Duisburg, Germany) at $60 \mathrm{rpm}$ for $10 \mathrm{~min}$ at the appropriate processing temperature. After mixing the filler with polyamide, the composites were cooled at room temperature. Abrasive paper was used to make a disc sample with $10 \mathrm{~mm}$ diameter and $1 \mathrm{~mm}$ thickness to measure the thermal diffusivity.

\subsection{Fourier transform infrared analysis}

To investigate the chemical functional groups on the GIC and graphite, Fourier transform infrared (FTIR) spectra were obtained with a Bruker EQUINOX 55 (Bruker Optics, Wissemburg, France) in the mid infrared range $\left(4000-400 \mathrm{~cm}^{-1}\right)$. The filler was ground with $\mathrm{KBr}$ powder and pressed into disc tablet to obtain the FTIR spectra.

Table 2. Properties of the graphite intercalated compound and graphite

\begin{tabular}{|l|c|c|}
\hline \multicolumn{1}{|c|}{ Properties } & Graphite intercalated compound & Graphite \\
\hline Particle size $[\mu \mathrm{m}]$ & 250 & 20 \\
\hline Onset expansion temperature $\left[{ }^{\circ} \mathrm{C}\right]$ & 250 & - \\
\hline Density $\left[\mathrm{kg} / \mathrm{m}^{3}\right]$ & 2000 & 2100 \\
\hline Bulk density $\left[\mathrm{kg} / \mathrm{m}^{3}\right]$ & 580 & 170 \\
\hline Shape & Flake & Flake \\
\hline
\end{tabular}




\subsection{Scanning electron microscopy}

A field emission scanning electron microscope (S-4500, JEOL, Tokyo, Japan) at an acceleration voltage of $10 \mathrm{kV}$ was used to observe the morphology of the fillers and the fractured surface of the composites. The composites were cryogenically fractured in liquid nitrogen. The samples were Ptcoated using a sputter coater (108, Cressington Scientific, Watford, UK) for 2 min before imaging to avoid charging during observation.

\subsection{Differential scanning calorimeter analysis}

To measure the heat of fusion and crystallinity of the virgin polyamides and composites, a differential scanning calorimeter (N-650, Scinco, Seoul, Korea) was used, a 10-15 mg sample was loaded in the Al pan and the experiments were conducted in a nitrogen atmosphere. The temperature range scanned was from 30 to $300^{\circ} \mathrm{C}$ at a heating rate of $20^{\circ} \mathrm{C} / \mathrm{min}$. The crystallnity $\left(\chi_{\mathrm{c}}\right)$ of the composites was calculated with the Equation (1):

$\chi_{\mathrm{c}}=\frac{\Delta H_{\mathrm{m}}}{\varphi \Delta H_{\mathrm{m}}^{0}} \cdot 100$

where $\Delta H_{\mathrm{m}}$ is the heat of fusion of the polyamide, $\varphi$ is the mass fraction of polyamide in the composites, and $\Delta H_{\mathrm{m}}^{0}$ is the heat of fusion of a $100 \%$ crystalline polyamide.

\subsection{Thermal diffusivity}

The thermal diffusivity $(\alpha)$ of the composites was measured by a laser flash method (TC-7000, ULVAC, Kanagawa, Japan) at $30^{\circ} \mathrm{C}$. The laser flash technique was introduced in 1961 by Parker et al. [9]. This technique measures the characteristic rise time. Laser heat pulses irradiated on the front side of the disc sample; the heat was transmitted through the sample thickness $(L)$ direction and was measured by an infrared camera. The time to reach the half of the maximum temperature $\left(t_{1 / 2}\right)$ at the back side of the sample was chosen to calculate the thermal diffusivity by Equation (2):

$\alpha=1.38 \frac{L^{2}}{\pi^{2} t_{1 / 2}}$

Due to nature of the phase delay technique, the measured property is the directional thermal diffusivity.

\section{Results and discussion}

\subsection{FTIR analysis}

Figure 1 shows the infra-red (IR) spectra of the heat treated GIC at $280^{\circ} \mathrm{C}$ and the spectra of graphite. The broad peak around $3435 \mathrm{~cm}^{-1}$ is attributed to absorbed water in the graphite GIC. The peak at $1397 \mathrm{~cm}^{-1}$ may be ascribed to $\mathrm{NO}_{3}^{-}$which originates from the $\mathrm{HNO}_{3}$ solution during the preparation step $[10,11]$. The large band centered at $1100 \mathrm{~cm}^{-1}$ of the GIC is attributed to sulphates. It indicates that traces of sulphuric acid are still present in the GIC after expansion. The peak in the $1500-1680 \mathrm{~cm}^{-1}$ region is assigned to aromatic $\mathrm{C}=\mathrm{C}$ bonds and various substitution modes of the aromatic ring. The peaks at $2900-2800 \mathrm{~cm}^{-1}$ of the GIC indicate the presence of aliphatic carbons. Such species may be produced during the degradation of graphite under air [12]. Oxygen functional groups on the surface of fillers may facilitate chemical interactions with the functional groups of the polyamide.

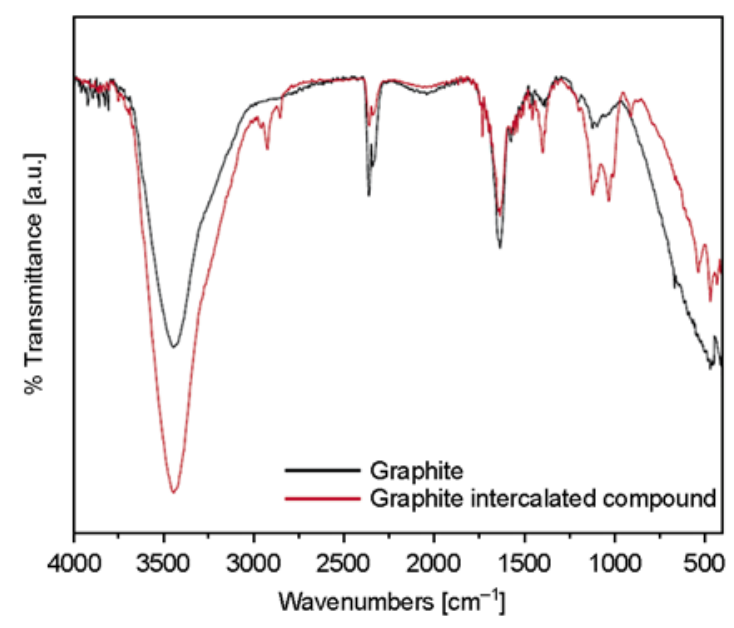

Figure 1. FTIR spectra of graphite and graphite intercalated compound (heat-treated at $280^{\circ} \mathrm{C}$ )

\subsection{Morphological characteristics}

The graphite, GIC, and polyamide based composites were observed by scanning electron microscope (SEM). Figure 2a shows the image of graphite flakes with average particle size of $20 \mu \mathrm{m}$. The GIC before expansion has a relatively smooth surface and some small flakes were observed on the surface of the GIC as shown in Figure 2b. The irregular flake shape of the GIC was similar to natural graphite flakes and the graphite stacks can be seen from the side view (not shown). The diameter and thickness of the GIC 


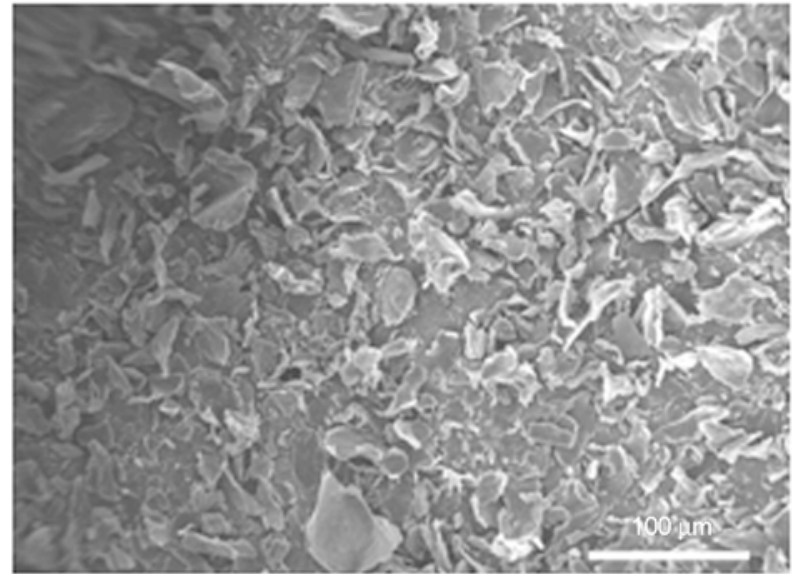

a)

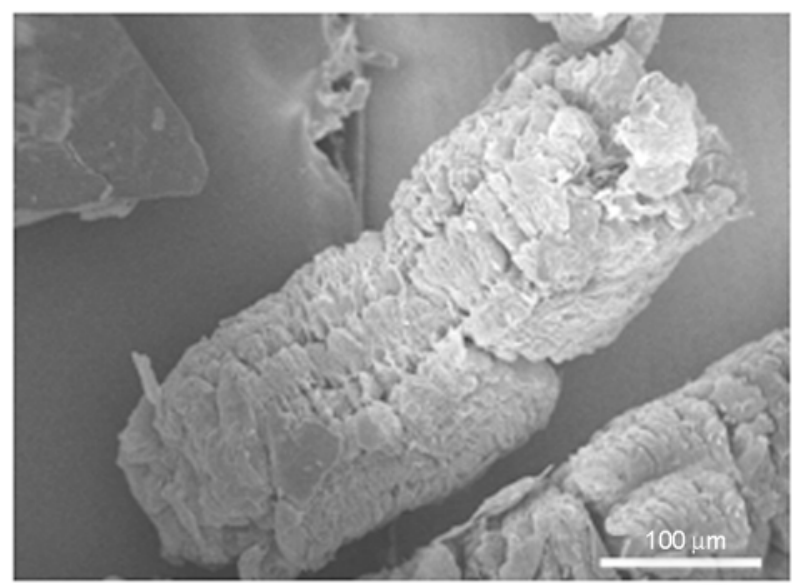

c)

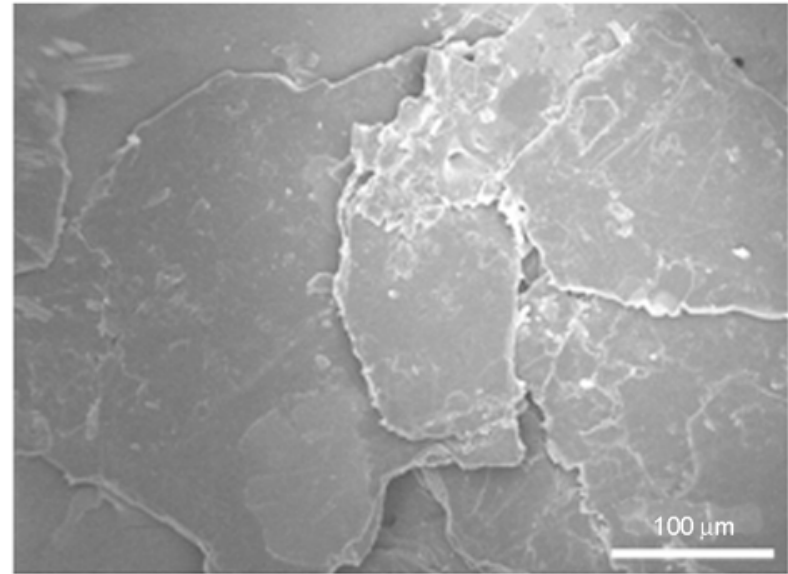

b)

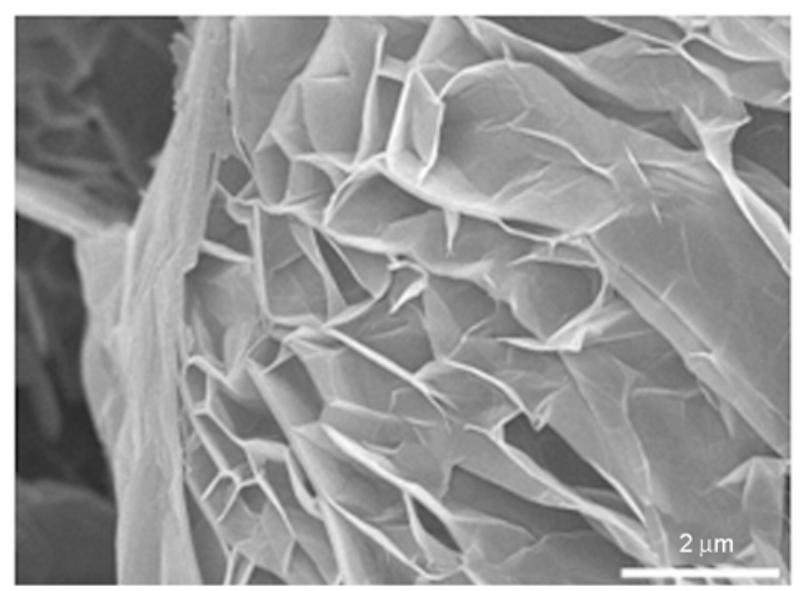

Figure 2. SEM images of (a) graphite $(\times 250)$, (b) graphite intercalated compound before expansion $(\times 250)$, (c) expanded graphite intercalated compound $(\times 250)$, and $(\mathrm{d})$ expanded graphite intercalated compound $(\times 10000)$

before expansion were about 150 and $10 \mu \mathrm{m}$, respectively. The worm-like structure of GIC was observed (Figure 2c) after heating to $280^{\circ} \mathrm{C}$. The SEM image at higher magnifications shows layered structures with thicknesses ranging from a few nanometers to a few micrometers (Figure 2d). Figures 3a-3c show the fractured SEM images of different polyamides based composites at $10 \mathrm{vol} \%$ of GIC loading after in-situ exfoliation processing.

The nanosheets of exfoliated/intercalated graphite were well dispersed in the all polyamide matrices during in-situ the exfoliation processing. The intercalated/exfoliated graphite structure was observed when the processing temperature was higher than the onset expansion temperature, i.e. $250^{\circ} \mathrm{C}$, for GIC. The distance between the expanded nanosheets was as large as several micrometers and the thickness of the exfoliated nanosheets in the polyamide matrix mostly ranged from 40 to $80 \mathrm{~nm}$, it decreased to as low as $7 \mathrm{~nm}$ after in-situ exfoliation processing (inset in Figure 3c).

Carbon atoms positioned in adjacent planes on the graphite layer are bound by weaker van der Waals forces. The weak interplanar forces allow for certain atoms, molecules, and ions to intercalate into the interplanar spaces of the graphite and the expansion ratio of GIC varies with temperature, heat treatment time, intercalating temperature etc. [5]. In general, the expansion ratio in $\mathrm{c}$ axis of the GIC is 200-300 [13]. The high expansion of the GIC during in-situ exfoliation could offer close contact between the matrix and exfoliated nanosheets and form 3-dimensional conductive pathways in the matrix.

We also used graphite as a filler to compare with the GIC. The average particle size of the graphite was $20 \mu \mathrm{m}$ and the thickness was ca. $2 \mu \mathrm{m}$. The graphite filler did not expand and a continuous graphite net- 


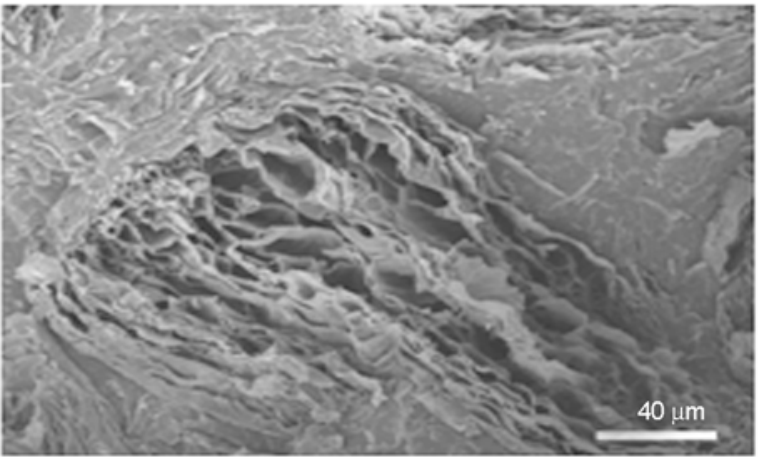

a)

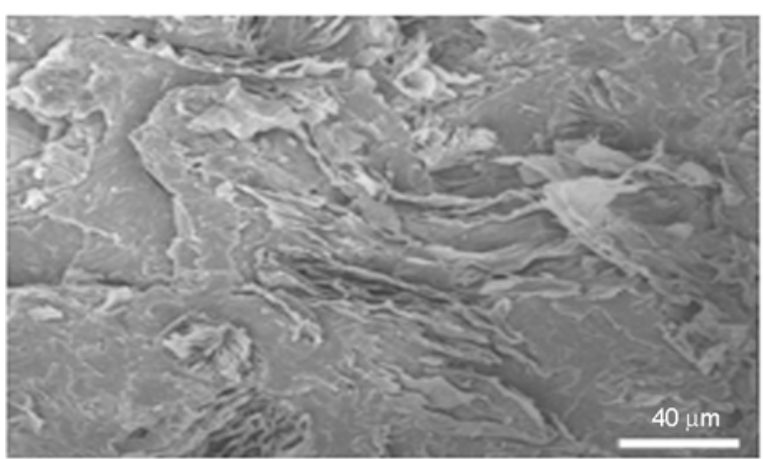

b)

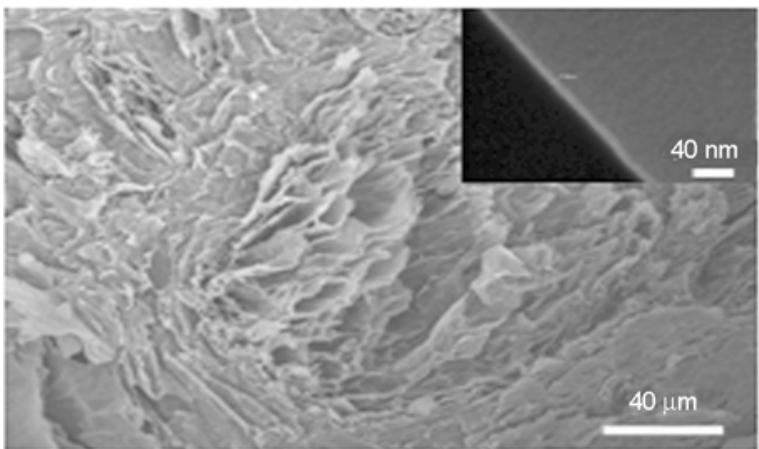

c)

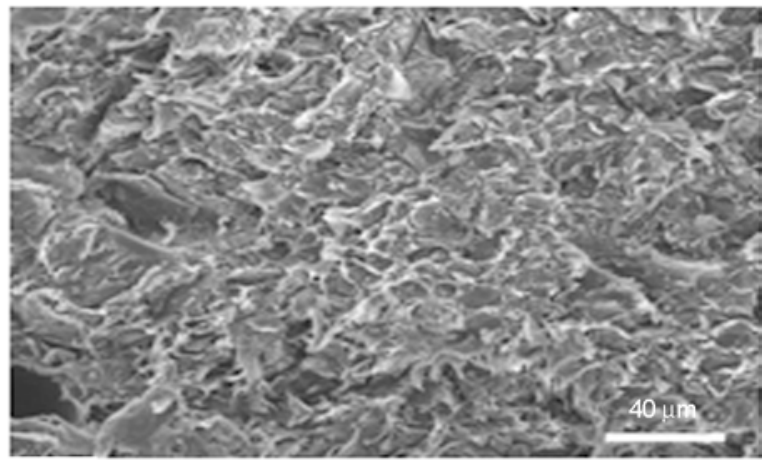

d)

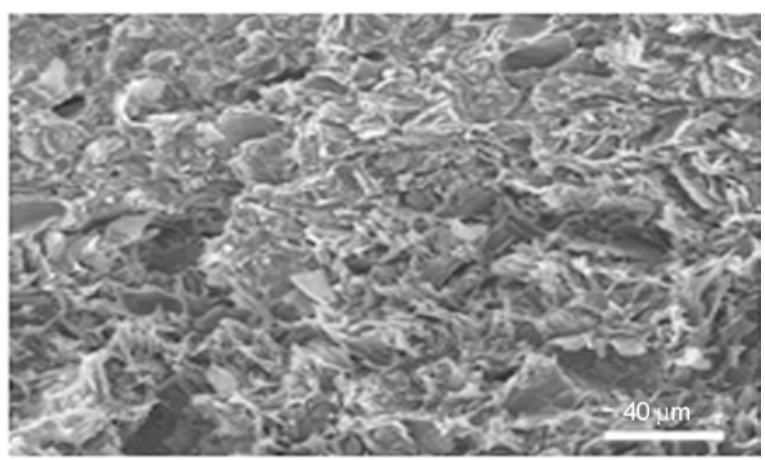

e)

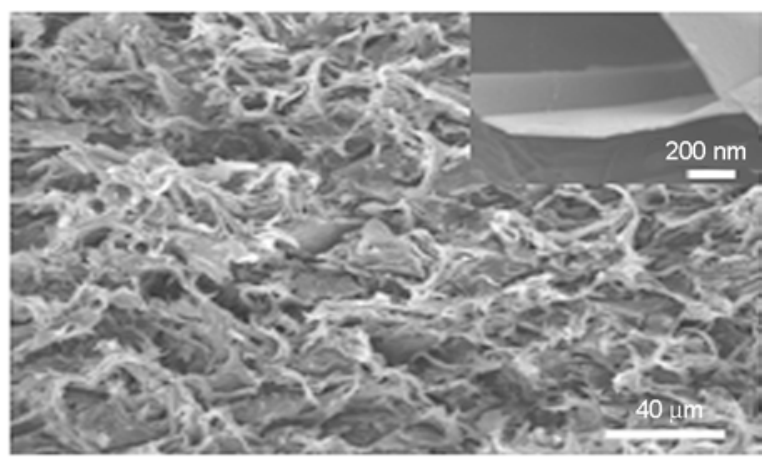

f)

Figure 3. SEM images of PA composites at 10 vol\% of fillers (a) PA6/GIC, (b) PA66/GIC, (c) PA12/GIC, (d) PA6/graphite, (e) PA66/graphite, and (f) PA12/graphite $(\times 500)$

work was not observed in the polyamide. Small graphite fillers in thermally insulating polyamide matrix could increase the thermal interface resistance which plays a critical role in heat transfer [14, 15]. As shown in Figures 3d-3f, the small graphite particles were dispersed well in the polyamide matrix after melt mixing. A graphite sheet thickness of ca. $50 \mathrm{~nm}$ was observed (inset of Figure $3 \mathrm{f}$ ).

The fracture surface of the PA12/graphite composite showed the elongated ligaments of the matrix due to the ductile nature of PA12. Exfoliation/intercalation of the GIC in the polyamide matrix resulted in a larger contact area between nanosheets (Figures $3 \mathrm{a}-3 \mathrm{c})$. Therefore, it is apparent that the phonon transfer of GIC based composites is much easier than that of graphite based composites.

To investigate the effect of the processing temperature of the graphite intercalated compound on the thermal diffusivity of the PA/GIC, two different processing temperatures, i.e., a temperature lower $\left(210^{\circ} \mathrm{C}\right)$ and the higher $\left(265^{\circ} \mathrm{C}\right)$ than the expansion temperature $\left(250^{\circ} \mathrm{C}\right)$ of GIC were chosen. Different processing temperatures led to a distinctive morphology of the composites, as shown in Figure 4. At lower temperature (Figure 4a), the graphite particles remained in a stacked form. At the higher processing temperature $\left(265^{\circ} \mathrm{C}\right)$, however, the GIC was exfoliated and the micro- and nanosheets were sep- 


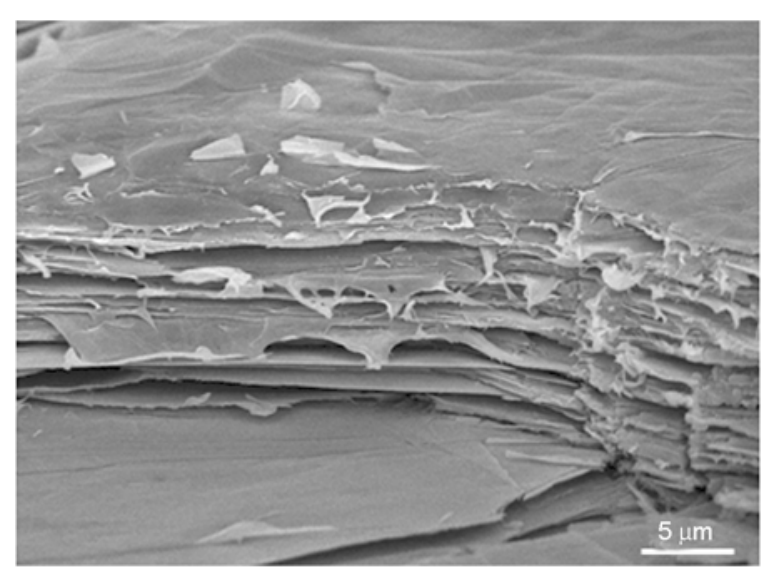

a)

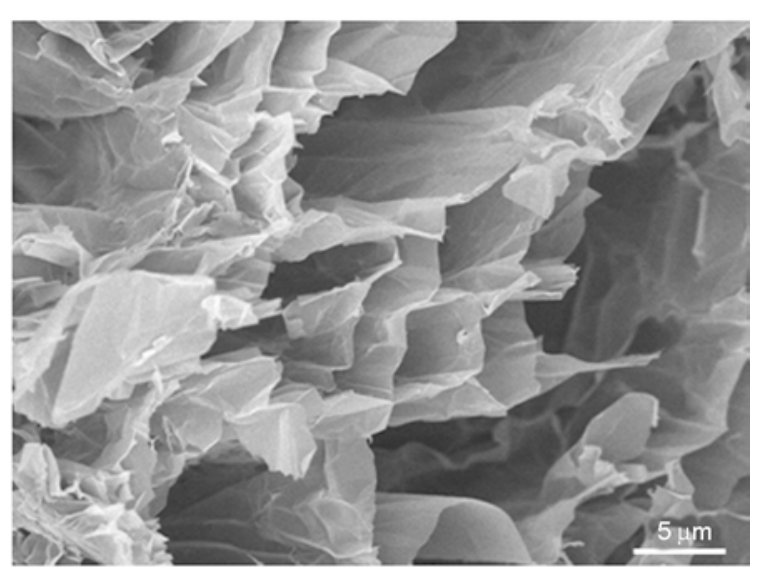

b)

Figure 4. SEM images of PA12/GIC composites processed (a) at $210^{\circ} \mathrm{C}$ and (b) at $265^{\circ} \mathrm{C}(\times 3000)$

arated and big spaces of up to $\sim 10 \mu \mathrm{m}$ between the graphite sheets were observed (Figure $4 b$ ). The higher expansion ratio and appropriate dispersion of the GIC at a higher processing temperature than the onset expansion temperature $\left(250^{\circ} \mathrm{C}\right)$, led to the exfoliation of the GIC and formed tightly connected thermal paths as shown in Figure $4 b$.

\subsection{Crystallinity}

To investigate the crytallinity effect on thermal diffusivity, the heat of fusion of the composite was measured using differential scanning calorimetry (DSC). The DSC melting curves of the polyamides and composites at $20 \mathrm{vol} \%$ of filler content are plotted in Figure 5, and related thermal properties derived from the DSC thermograms are summarized in Table 3. Table 3 shows the Tm, crystallinity and thermal diffusivity of different polyamides and composites. The crystallinities of pure PA6, PA66, and PA12 were 46.9, 41.1 and $24.7 \%$, respectively. The presence of intercalated/exfoliated graphite sheets may also affect the crystallization behavior of the polyamides. The crystallinity at $20 \mathrm{vol} \%$ of graphite and graphite intercalated compounds are

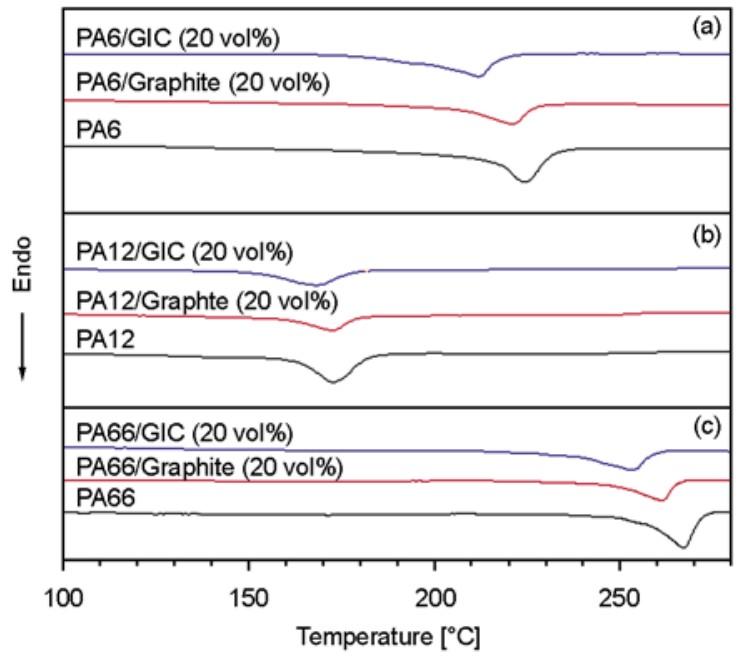

Figure 5. Melting curves of polyamides and PA composites by DSC (a) PA6, (b) PA12, and (c) PA66

lower than that of pure polyamide 6 . The crystallinity was higher in the GIC filled composite compared to the graphite filled composite. The graphite nanosheets in the composites may induce transcrystallization and the higher surface of exfoliated/intercalated GIC compared to the graphite could provide more filler surface for crystal nucleation and result in the higher crystallinity. The longer methylene

Table 3. DSC results and the thermal diffusivity of pure polyamides and composites

\begin{tabular}{|l|c|c|c|c|}
\hline \multicolumn{1}{|c|}{ Sample } & $\left.\mathbf{T}_{\mathbf{m}}{ }^{\circ}{ }^{\circ} \mathbf{C}\right]$ & $\Delta \mathbf{H}_{\mathbf{m}}[\mathbf{J} / \mathbf{g}]$ & $\chi_{\mathbf{c}}{ }^{\mathbf{}}[\mathbf{\%}]$ & Thermal diffusivity $\left[\mathbf{m}^{2} / \mathbf{s}\right]$ \\
\hline PA6 & 224.2 & 89.3 & 46.9 & $1.59 \cdot 10^{-7}$ \\
\hline PA6/Graphite (20 vol\%) & 219.0 & 49.7 & 26.1 & $1.23 \cdot 10^{-6}$ \\
\hline PA6/GIC (20 vol\%) & 211.9 & 58.0 & 30.4 & $2.59 \cdot 10^{-6}$ \\
\hline PA66 & 266.9 & 78.1 & 41.1 & $1.58 \cdot 10^{-7}$ \\
\hline PA66/Graphite (20 vol\%) & 261.3 & 42.1 & 27.7 & $2.40^{-6}$ \\
\hline PA66/GIC (20 vol\%) & 250.3 & 46.8 & 30.8 & $1.22 \cdot 10^{-6}$ \\
\hline PA12 & 172.6 & 37.5 & 24.7 & $8.63 \cdot 10^{-7}$ \\
\hline PA12/Graphite (20 vol\%) & 171.0 & 22.4 & 13.4 & $2.59 \cdot 10^{-6}$ \\
\hline PA12/GIC (20 vol\%) & 167.6 & 33.2 & 19.8 & \\
\hline
\end{tabular}

${ }^{a}$ The heat of crystallization of $100 \%$ crystalline PA6 [16], PA66 [17], and PA12 [18] is 202.7, 190.0, and 209.2 J/g, respectively. 
group and the smaller amount of hydrogen bonding in the PA12 compare to the PA6 and PA66 leads to the less chain alignment and lower crystallinity.

The crystalline part conducts phonon better than the amorphous part [19]. In graphite containing composites, the thermal diffusivity of matrix is dominant and the higher crystallinty of PA6 and PA66 compared to that of PA12 may result in the higher thermal diffusivity of PA6/graphite and PA66/ graphite. However, in GIC containing PA composites, the 3-dimensional network of GIC may be dominant at higher volume percentage as a result of insitu exfoliation than the thermal diffusivity of matrix and the thermal diffusivity of PAs/GIC (20 vol\%) composites was similar among polyamide grades.

The melting temperatures of PA/GIC composites shift toward a lower temperature, which is potentially related to the reduction of hydrogen bonding between polyamide molecules by the presence of nanoscale graphite sheets and imperfect crystals [20].

\subsection{Thermal diffusivity}

Figure 6 shows the thermal diffusivity of three different polyamides based composites as a function of filler loading. The thermal diffusivity linearly increased with increasing filler content due to the decrease of distance and the increase of the overlapped area of graphite fillers. However, there was a noticeable difference in the heat conducting capability of the GIC, ExGIC and graphite based composites. The thermal diffusivity of the PA/GIC was higher than that of the PA/graphite composites in all volume percentages. The higher expansion ratio and

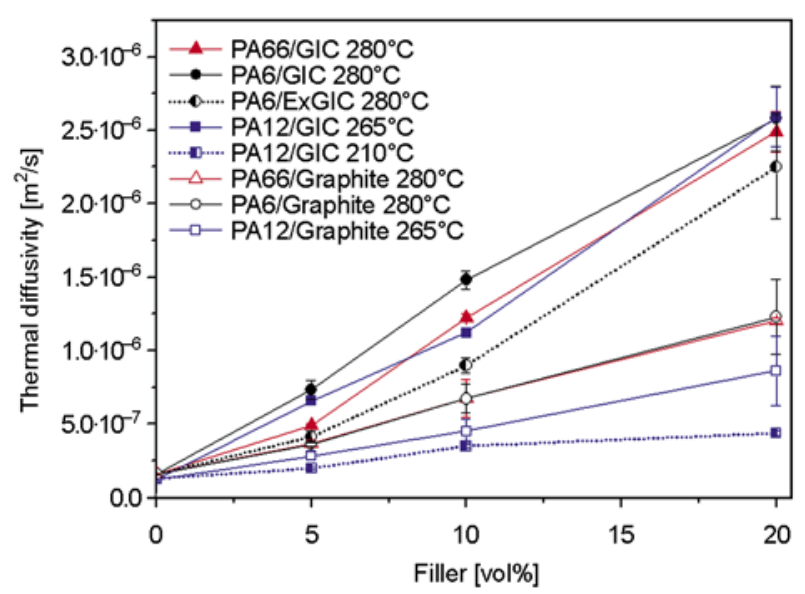

Figure 6. Thermal diffusivity of the PAs/GIC, PA6/ExGIC, and PAs/graphite composites as a function of filler loading the larger diameter, of up to tens of micrometers, of the exfoliated/intercalated sheets and the functional groups on the surface in the exfoliated/intercalated graphite may be responsible for the higher thermal diffusivity. Most of the heat transfer occurs by phonons in the polymer composites and there is less phonon scattering in the largely overlapped PA/GIC which leads to a high thermal diffusivity. The smaller graphite particles than those in the GIC act as phonon scattering centers and further impede the heat transfer from graphite particle to graphite particle. Phonon transfer across the interface is hindered and the thermal resistance of the interface, also called the Kapitza resistance, represents a barrier to heat flow associated with differences in the phonon spectra of the two phases. In PA/graphite (20 vol\%) composites, the small sized graphite particles resulted in a reduction of more than $50 \%$ in the thermal diffusivity compared with the in-situ exfoliated GIC/PA composites.

The thermal diffusivity of randomly oriented GIC/ polyamide composites was increased to $2.59 \cdot 10^{-6} \mathrm{~m}^{2} / \mathrm{s}$ at $20 \mathrm{vol} \%$. This is an increase of approximately 18 times compared to pure polyamides. This magnitude is comparable to the through-plane thermal diffusivity, $3.28 \cdot 10^{-6} \mathrm{~m}^{2} / \mathrm{s}$, of polyetherimide $(1.5 \mathrm{wt} \%)$ /graphite nanoplatelets (xGnP-15, $98.5 \mathrm{wt} \%$ ) paper prepared by vacuum filtration method [21].

It should be noted that the thermal diffusivity of the three different polyamides based composites at $20 \mathrm{vol} \%$ of graphite intercalated compound was similar. The dominant contribution of thermal diffusivity from the in-situ exfoliated graphite sheets over the PA matrix could be a reason for the similar thermal diffusivity of three PA/GIC composites.

The PA6/ExGIC composites showed a lower thermal diffusivity than the in-situ processed PA6/GIC composites. It could be related to significant lateral size reduction of graphite platelets in ExGIC during melt mixing (not shown). The smaller size and overlap of graphite platelets in polymer matrix is not beneficial for phonon transfer and it may result in lower thermal diffusivity than that of in-situ processed PAs/GIC composites.

The thermal diffusivity of PA12/graphite (20 vol\%) composites was the lowest among all the composites at same filler content. The fracture surface of PA12/graphite composite (Figure 3f) shows the 
higher number of elongated fibrils compared to that of PA6- and PA66 based composites (Figure 3d, 3e). The longer methylene segment and the lower crystallinity of PA12 could lead to better graphite dispersion and the elongated fibril structure without formation of thermally conductive pathways. It could increase the interfacial thermal resistance or the phonon scattering and consequently could lower the thermal diffusivity.

The thermal diffusivity of the PA12/GIC was significantly increased by changing the processing temperature from 210 to $265^{\circ} \mathrm{C}$ as shown in Figure 6. This is explained by the expansion of the GIC, as shown in Figure 4. The GIC remained in stacked at the lower processing temperature, $210^{\circ} \mathrm{C}$, and the thermal diffusivity of the PA12/GIC composite was $3.83 \cdot 10^{-7} \mathrm{~m}^{2} / \mathrm{s} \mathrm{m}^{2} / \mathrm{s}$ at $20 \mathrm{vol} \%$, this slightly increased with increasing GIC content. However, the thermal diffusivity of the PA/GIC composite increased rapidly with GIC content when processed at $265^{\circ} \mathrm{C}$. Here the thermal diffusivity was 7 times higher, $2.59 \cdot 10^{-6} \mathrm{~m}^{2} / \mathrm{s}$, than that of the sample processed at $210^{\circ} \mathrm{C}$. There was little change in the thermal diffusivity with respect to processing temperature in the graphite based PA composites (not shown).

\section{Conclusions}

Highly thermally conductive polyamide composites were developed using in-situ exfoliation of graphite intercalated compound and the thermal diffusivity of the PA/GIC composites was compared to the $\mathrm{PA} /$ graphite composites. The PA/GIC composites showed considerably greater improvements in thermal diffusivity compared to the PA/ExGIC and PA/ graphite composites. The thermal diffusivity of PA66/GIC (20 vol\%) was increased 18 times compared to that of pure PA66. The larger particle size, high expansion ratio, the surface chemistry and the formation of 3-dimensional thermally conductive pathways of GIC resulted in this high thermal diffusivity. The thermal diffusivity of the in-situ exfoliated PA/GIC composite was comparable to that of through-plane graphite nanoplatelet $(\mathrm{xGnP})$ paper prepared by vacuum filtration method. The high thermal diffusivity was obtained when the melt processing temperature was higher than the onset temperature of expansion. Utilization of in-situ exfoliated GIC in other polymeric matrixes or in hybrid composites could offer promising thermal diffusivity at a reasonable cost.

\section{Acknowledgements}

This research was financially supported by the Ministry of Education, Science Technology of Korea through the Human Resource Training Project for Regional Innovation and the Fundamental R \& D Program for Core Technology of Materials which are sponsored by the Ministry of Knowledge Economy of the Korean Government.

\section{References}

[1] Vettegren V. I., Bashkarev A. Ya., Suslov M. A.: Thermal diffusivity of antifriction polymer composites. Technical Physics Letters, 33, 869-871 (2007). DOI: $10.1134 / \mathrm{S} 1063785007100185$

[2] Singh V., Joung D., Zhai L., Das S., Khondaker S. I., Seal S.: Graphene based materials: Past, present and future. Progress in Materials Science, 56, 1178-271 (2011). DOI: $10.1016 /$ j.pmatsci.2011.03.003

[3] Zheng W., Wong S-C., Sue H-J.: Transport behavior of PMMA/expanded graphite nanocomposites. Polymer, 43, 5767-5773 (2002). DOI: $10.1016 / \mathrm{S} 0032-3861(02) 00599-2$

[4] Chen G-H., Wu D-J., Weng W-G., He B., Yan W-L.: Preparation of polystyrene-graphite conducting nanocomposites via intercalation polymerization. Polymer International, 50, 980-985 (2001). DOI: $10.1002 /$ pi.729

[5] Li Y-C., Chen G-C.: HDPE/expanded graphite nanocomposites prepared via masterbatch process. Polymer Engineering and Science, 47, 882-888 (2007). DOI: $10.1002 /$ pen.20772

[6] Fukushima H., Drzal L. T., Rook B. P., Rich M. J.: Thermal conductivity of exfoliated graphite nanocomposites. Journal of Thermal Analysis and Calorimetry, 85, 235-238 (2006). DOI: $10.1007 / \mathrm{s} 10973-005-7344-\mathrm{x}$

[7] Uhl F. M., Yao Q., Nakajima H., Manias E., Wilkie C. A.: Expandable graphite/polyamide- 6 nanocomposites. Polymer Degradation and Stability, 89, 70-84 (2005).

DOI: 10.1016/j.polymdegradstab.2005.01.004

[8] Zheng W., Wong S-C.: Electrical conductivity and dielectric properties of PMMA/expanded graphite composites. Composites Science and Technology, 63, 225235 (2003). DOI: $10.1016 / \mathrm{S} 0266-3538(02) 00201-4$

[9] Parker W. J., Jenkins R. J., Butter C. P., Abbot G. L.: Flash method of determining thermal diffusivity, heat capacity, and thermal conductivity. Journal of Applied Physics, 32, 1679-1684 (1961).

DOI: $10.1063 / 1.1728417$ 
[10] Nakamoto K.: Infrared and Raman spectra of inorganic and coordination compounds. Wiley, New York (1997).

[11] Zhang S., Gu A., Gao H., Che X.: Characterization of exfoliated graphite prepared with the method of secondary intervening. International Journal of Industrial Chemistry, 2, 123-130 (2011).

[12] Duquesne S., Le Bras M., Bourbigot S., Delobel R., Vezin H., Camino G., Eling B., Lindsay C., Roels T.: Expandable graphite: A fire retardant additive for polyurethane coatings. Fire and Materials, 27, 103-117 (2003).

DOI: $10.1002 /$ fam.812

[13] Pan Y-X., Yu Z-Z., Ou Y-C., Hu G-H.: A new process of fabricating electrically conducting nylon 6/graphite nanocomposites via intercalation polymerization. Journal of Polymer Science Part B: Polymer Physics, 38, 1626-1633 (2000).

DOI: 10.1002/(SICI)1099-0488(20000615)38:12<1626 $\because$ AID-POLB80>3.0.CO;2-R

[14] Nan G-W., Liu G., Lin Y., Li M.: Interface effect on thermal conductivity of carbon nanotube composites. Applied Physics Letters, 85, 3549-3551 (2004). DOI: $10.1063 / 1.1808874$

[15] Huxtable S. T., Cahill D. G., Shenogin S., Xue L., Ozisik L., Barone P., Usrey M., Strano M. S., Siddons G., Shim M., Keblinski P.: Interfacial heat flow in carbon nanotube suspensions. Nature Materials, 2, 731734 (2003).

DOI: $10.1038 /$ nmat996
[16] Chao L-C., Chang E-P.: Interaction of anhydrous ferric chloride with nylon 6. Journal of Applied Polymer Science, 26, 603-610 (1981).

DOI: 10.1002/app.1981.070260219

[17] Prime R. B.: Thermosets. in 'Thermal characterization of polymeric materials’ (ed.: Turi E.) Academic Press, San Diego, 1380-1766 (1997).

[18] Gogolewski S., Czerntawska K., Gastorek K.: Effect of annealing on thermal properties and crystalline structure of polyamides. Nylon 12 (polylaurolactam). Colloid and Polymer Science, 258, 1130-1136 (1980). DOI: $10.1007 / \mathrm{BF} 01382456$

[19] Han Z., Fina A.: Thermal conductivity of carbon nanotubes and their polymer nanocomposites: A review. Progress in Polymer Science, 36, 914-944 (2011). DOI: 10.1016/j.progpolymsci.2010.11.004

[20] Zhou H., Zhang S., Yang M.: The thermal conductivity of Nylon 6/clay nanocomposites. Journal of Applied Polymer Science, 108, 3822-3827 (2008). DOI: 10.1002 app. 27984

[21] Xiang J., Drzal L. T.: Thermal conductivity of exfoliated graphite nanoplatelet paper. Carbon, 49, 773-778 (2011).

DOI: $\underline{10.1016 / \text { j.carbon.2010.10.003 }}$ 